\title{
ENHANCED PHOTOCATALYTIC ACTIVITY OF TiO, FILMS BY MODIFICATION WITH POLYETHYLENE GLYCOL
}

\author{
Álvaro A. Ramírez-Santos, Próspero Acevedo-Peña and Elcy M. Córdoba* \\ Universidad Industrial de Santander, Calle 9 Cra. 27, Postal code 678 Bucaramanga (Santander), Colombia
}

Recebido em 15/1/12; aceito em 22/6/12; publicado na web em 18/9/12

\begin{abstract}
Titanium dioxide porous thin films on the Anatase phase were deposited onto glass slides by the sol-gel method assisted with polyethylene glycol (PEG). The dip-coated films were characterized using scanning electron microscopy (SEM), thermogravimetric analysis (TGA and DTG), UV-visible spectroscopy and X-ray diffraction (XRD). The photocatalytic activity of the films was determined by means of methyl-orange oxidation tests. The resultant PEG-modified films were crack-free and developed a porous structure after calcination at $500{ }^{\circ} \mathrm{C}$. Photo-oxidation tests showed the dependency of catalytic activity of the films on the number of layers (thickness) and porosity, i.e. of the interfacial area.
\end{abstract}

Keywords: polyethylene glycol (PEG); photocatalysis; $\mathrm{TiO}_{2}$ films.

\section{INTRODUCTION}

Titanium dioxide is a semiconductor material with high chemical stability over a wide $\mathrm{pH}$ range, a high resistance under illumination (low photo-corrosion), aside from having the advantages of being non-toxic, safe, relatively abundant. Owing to the absolute energy position of the conduction and valence band of titanium dioxide, it is capable of participating in strong oxidation-reduction reactions. Given these characteristics, $\mathrm{TiO}_{2}$ is the most commonly employed material in photocatalytic applications. ${ }^{1-3}$

Several techniques have been employed in the fabrication of $\mathrm{TiO}_{2}$ thin films: Sputtering, ${ }^{4}$ electrophoretic deposition, ${ }^{5,6}$ sol-gel deposition, ${ }^{7}$ and spray pyrolysis, ${ }^{8}$ to cite the most common. Amongst these, the sol-gel route is the widest used, due to the low sintering temperatures required, process versatility and homogeneity at the molecular level. ${ }^{9}$ In sol-gel reactions, a precursor metal alkoxide of the type $\mathrm{Ti}(\mathrm{OR})_{4}(\mathrm{R}=$ alkyl groups $)$ is hydrolyzed under controlled conditions, forming a three-dimensional network of $\mathrm{TiO}_{6}$ octahedral units. The stable $\mathrm{TiO}_{2}$ sols are used to impregnate the substrates and form the oxide coating by dip or spin-coating techniques. ${ }^{10}$

Both the optical and photocatalytic properties of the $\mathrm{TiO}_{2}$ coatings depend upon the crystalline structure, crystallite size, and thickness and porosity of the films. A highly porous superficial structure is desirable, because it offers a greater number of catalytic sites. ${ }^{11}$ The formation of thin films with good pore-size distribution and without delamination or cracking during the calcination process, is technically challenging; but there have been successful examples. Recent studies have pointed to the use of certain organic compounds called polymeric fugitive agents (PFA's). PFA's are able to produce, after thermal treatments and without obstructing gelation, crack-free porous films. ${ }^{12-15}$ These kinds of films are expected to lead to superior catalytic activities compared to dense films. In principle, the morphology and microstructure of the $\mathrm{TiO}_{2}$ film can be adjusted by introducing the polymeric agent during sol-gel synthesis.

Methyl-orange oxidation has proven an efficient tool for evaluating the photocatalytic activity of $\mathrm{TiO}_{2}$. Currently, it is widely used because of the amount of information available in the literature and the technical ease involved in the tracing or screening of the reactive concentration over time. ${ }^{16-18}$

\footnotetext{
*e-mail: ecordoba@uis.edu.co
}

In this study, a simple methodology for the preparation of porous thin films supported on glass slides was developed, using PEG as a polymeric additive. The multilayered films were characterized using the following techniques: thermogravimetric analysis (TGA-DTG), X-ray diffraction (XRD), UV-Vis spectroscopy and scanning electron microscopy (SEM). The effect of the PEG concentration and molecular weight, as well as the number of layers of $\mathrm{TiO}_{2}$ deposited, on the photocatalytic degradation of methyl-orange in aqueous solution was studied.

\section{EXPERIMENTAL}

\section{Obtention of $\mathrm{TiO}_{2}$ sols}

The titania sols were prepared using titanium tetraisopropoxide (97\%, Aldrich) as the $\mathrm{TiO}_{2}$ precursor, isopropanol (98\%, Carlo Erba) as the solvent, acetylacetone ( $99 \%$ Aldrich) as the sol stabilizer, acetic acid (100\%, Merck) as the $\mathrm{pH}$ adjuster and granular polyethylene glycol with a molecular weight of 3350 and $8000 \mathrm{~g} \mathrm{~mol}^{-1}$ (Carbowax) as the template for pore formation. The sols were prepared at room temperature, using the following route: $2.6 \mathrm{~mL}$ of acetylacetone was first added to $12.5 \mathrm{~mL}$ of isopropanol under constant stirring for $30 \mathrm{~min}$. Subsequently, $5 \mathrm{~mL}$ of titanium tetraisopropoxide was added to the above solution and the mixture maintained for $30 \mathrm{~min}$ under stirring. Next, $2.4 \mathrm{~mL}$ of de-ionized water was added dropwise, and the solution stirred for $15 \mathrm{~min}$. Finally, the $\mathrm{pH}$ was adjusted to 4 with acetic acid and polyethylene glycol added at three different concentrations $\left(0,12\right.$ and $\left.24 \mathrm{~g} \mathrm{~L}^{-1}\right)$. The sols were maintained under stirring for two hours. Thermal analyses were carried out on the xerogels obtained after desiccation of the sols at $50{ }^{\circ} \mathrm{C}$ for 24 hours. These analyses were done at a heating rate of $5^{\circ} \mathrm{C} \mathrm{min}-1$ under an air atmosphere and air flow of $20 \mathrm{~mL} \mathrm{~min}{ }^{-1}$.

\section{Deposition and characterization of $\mathrm{TiO}_{2}$ films}

The $\mathrm{TiO}_{2}$ films were deposited onto transparent glass slides $(25 \times 15 \times 1 \mathrm{~mm})$. Before immersion, the substrates were washed with 2-propanol for $30 \mathrm{~min}$ in an ultrasonic bath and dried by an air flow at room temperature. The coatings were deposited by the dip-coating technique onto the corresponding sol at a speed of $10 \mathrm{~cm} \mathrm{~min}^{-1}$. After deposition, the films were dried at room temperature within a 
desiccator for $3 \mathrm{~h}$ and were heat treated at $500{ }^{\circ} \mathrm{C}$ for $1 \mathrm{~h}$ at a heating rate of $5{ }^{\circ} \mathrm{C} \mathrm{min}{ }^{-1}$. This process was repeated in a cyclic manner for each deposited layer.

The number of layers deposited in each sample film varied, and films comprising 1, 3 and 5 layers were chosen for this study. The effect of the number of layers, and of PEG concentration and molecular weight, on the optical, crystalline and morphologic properties of the films was examined by UV-Visible spectroscopy in a 200$800 \mathrm{~nm}$ range, by $\mathrm{X}$-ray diffraction (using $\mathrm{Cu} \mathrm{K}$ radiation operating at $40 \mathrm{kV}$ and $40 \mathrm{~mA}$ ), and scanning electron microscopy (operating between 5 and $15 \mathrm{kV}$ ).

\section{Photocatalytic activity evaluation}

Methyl orange oxidation was used to evaluate the photocatalytic activity of the PEG-modified films with different deposited layers. The photoreactor, shown in Figure 1, consisted of a quartz-refrigerated jacket equipped with a UV lamp (Pen-Ray, $5 \mathrm{~W}$ ), over which the $\mathrm{TiO}_{2}$ film was fixed. This system was immersed within the methyl orange solution, under stirring and air bubbling. The whole system was shielded inside a black box to avoid interference from the laboratory lights. The reaction volume was $40 \mathrm{~mL}$ in all cases, with a methyl orange concentration of $5 \mathrm{ppm}$. Before reaction, the reactor was kept in darkness for 15 min under vigorous stirring and air bubbling to promote adsorption of the methyl orange onto the $\mathrm{TiO}_{2}$ surface. The air bubbling provided dissolved oxygen on the $\mathrm{TiO}_{2}$ surface to scavenge the free electrons, thus preventing recombination of electron-hole pairs. ${ }^{19}$ In all experiments, the solution temperature was kept at around $25^{\circ} \mathrm{C}$ by means of the refrigerated jacket containing the UV lamp. Methyl orange degradation was monitored by colorimetry, employing the absorption band at $460 \mathrm{~nm}$.

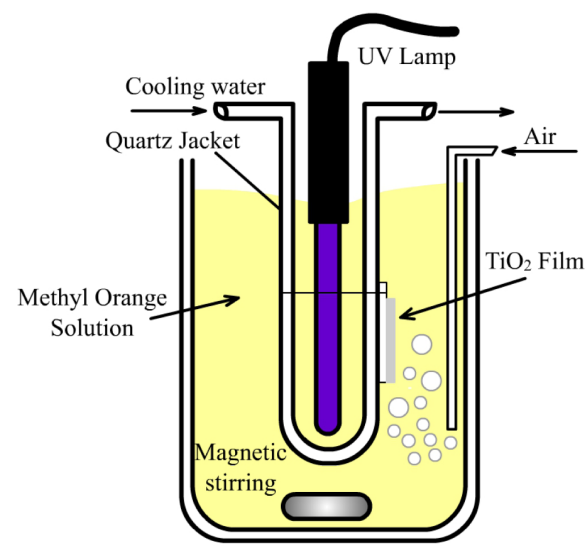

Figure 1. Schema of the reactor employed for the methyl orange photo oxidation

\section{RESULTS AND DISCUSSION}

\section{Thermal analysis of xerogels}

The thermogravimetric analyses are shown in Figure 2. In all cases, the xerogels obtained from the PEG-modified sols showed a higher weight loss than non-modified sol. Weight-loss values of $47.73,49.76,54.43$, and $51.65 \%$ were noted for samples with no PEG and with $12 \mathrm{~g} \mathrm{~L}^{-1}$ PEG 3350, $24 \mathrm{~g} \mathrm{~L}^{-1}$ PEG 3350 and $12 \mathrm{~g} \mathrm{~L}^{-1}$ PEG 8000 , respectively, after heating to $600{ }^{\circ} \mathrm{C}$. The greatest mass loss for all the samples occurred up to approximately $400{ }^{\circ} \mathrm{C}$, implying that the decomposition of the organic products was promoted below this temperature.

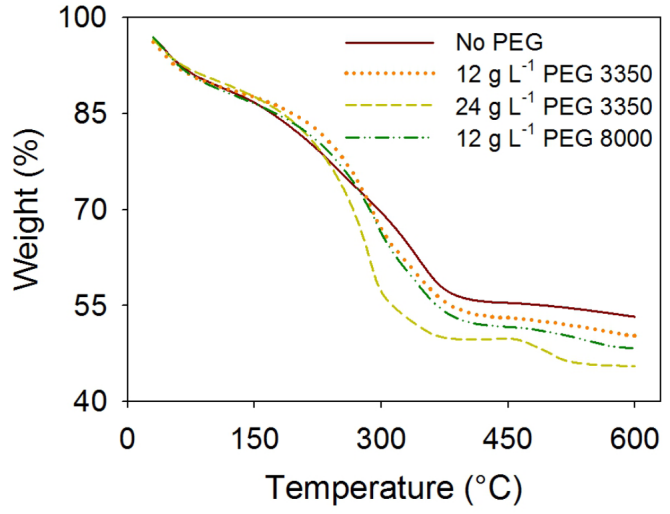

Figure 2. Thermogravimetric analyses of the xerogels

Figure 3 shows the first order derivatives of Figure 2 with respect to temperature (DTG curves). All the thermograms show a peak between 30 and $100^{\circ} \mathrm{C}$, caused by the removal of physisorbed water. A pronounced peak located between 200 and $300{ }^{\circ} \mathrm{C}$ is evident for the PEG-containing systems, and between 300 and $400{ }^{\circ} \mathrm{C}$ for the system without PEG. As these peaks correspond to noticeable weight losses, they were attributed to the combustion of organic compounds such as the solvent, stabilizer, alkoxide, and the PEG. ${ }^{20}$ As a case apart, the $24 \mathrm{~g} \mathrm{~L}^{-1} \mathrm{PEG} 3350$ sol showed a small peak between 450 and $500{ }^{\circ} \mathrm{C}$, attributed to remaining organic compounds in the sample.

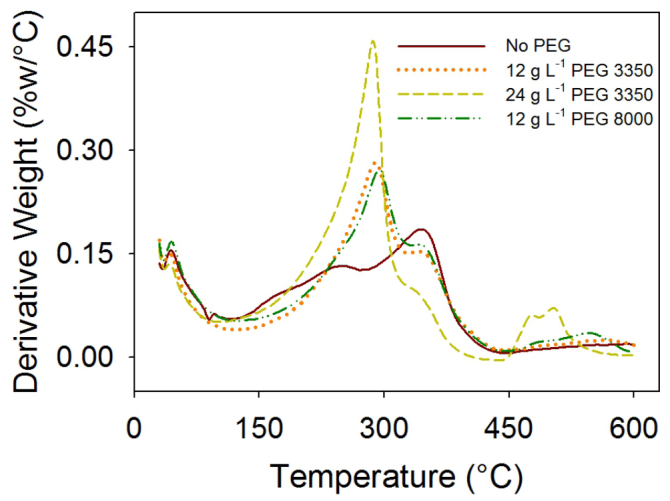

Figure 3. Differential thermogravimetry (DTG) for the xerogels

\section{Characterization of $\mathrm{TiO}_{2}$ films}

\section{$X$-ray diffraction}

Figure 4 shows the diffractograms of the 5-layer films heat treated at $500{ }^{\circ} \mathrm{C}$. As in all thin films, the peaks are of low intensity due to the amount of material present and the size of the crystallites. ${ }^{21} \mathrm{On}$ all the diffractograms, the most representative peak is that situated around $2 \theta=25.3^{\circ}$, corresponding to the plane (101) of Anatase, typical result for films heat treated at $500{ }^{\circ} \mathrm{C} .{ }^{22}$ The diffractograms of the PEG-modified films show the same peaks as the unmodified film and also a similar intensity, which is clear evidence that PEG does not intervene in the crystallization process at the chosen temperature, as reported by other authors. ${ }^{11}$ Moreover, the crystallite size of the $\mathrm{TiO}_{2}$ in the films was estimated by using the Scherrer equation from the peak broadening of the Anatase (101) diffraction as follows: ${ }^{23}$

$$
D=\frac{K \cdot \lambda}{\beta \cdot \cos \theta}
$$

where $K=0.9$ is the Scherrer coefficient, $\lambda=1.540598 \AA$ is the 
$\mathrm{Cu} \mathrm{K} \alpha$ radiation wavelength, $\beta$ is the full width at half maximum (FWHM) of the diffraction peak, and $\theta$ is the diffraction angle of the diffraction peak in question.

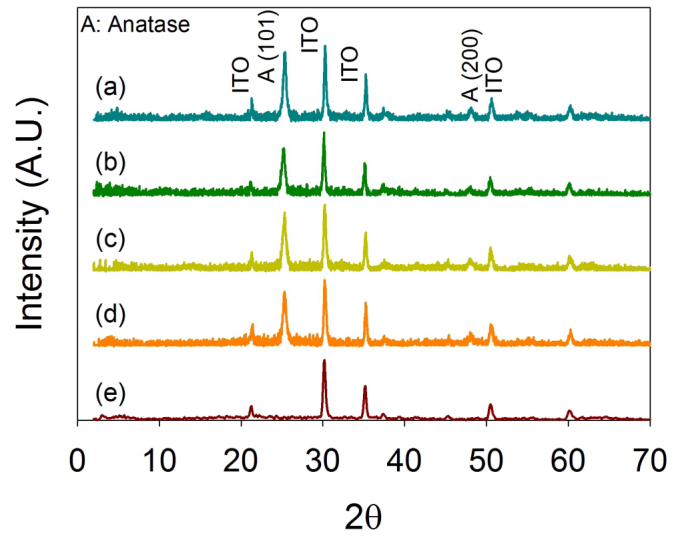

Figure 4. Difraction patterns of the $500{ }^{\circ} \mathrm{C}$ heat treated films (5 layers): (a) Blank substrate (ITO glass), (b) No PEG, (c) $12 \mathrm{~g} \mathrm{~L} \mathrm{~L}^{-1}$ PEG 3350, (d) $24 \mathrm{~g} \mathrm{L^{-1 }}$ PEG 3350, (e) $12 \mathrm{~g} \mathrm{~L}^{-1}$ PEG 8000

The values of $D$ (crystallite size of $\mathrm{TiO}_{2}$ ) for each film are summarized in the Table 1 as well as the absolute error in $D$. It is observed that crystallite size lies within a narrow range (13.6 to $18.1 \mathrm{~nm}$ ) and it can therefore be concluded that adding PEG has no significant influence on crystallite size of the $\mathrm{TiO}_{2}$ in the films. For this reason, any change in their photocatalytic activity caused by the PEG is not related to a decrease or increase in the crystallite size of the material, but to the surface area increment caused during the calcination process, an assertion verified by SEM images in the following section. Additionally, the supplementary materials were present in the UV-Vis study of the films, which showed that the presence of PEG does not induce modifications in the band-gap of the $\mathrm{TiO}_{2}$ films.

Table 1. Anatase crystallite size estimated from DRX spectra measured for the $\mathrm{TiO}_{2}$ films formed with 5 layers

\begin{tabular}{|c|c|c|}
\hline $\mathrm{TiO}_{2}$ Film & $\begin{array}{c}\text { Crystallite size } \\
D(\mathrm{~nm}) \\
\end{array}$ & $\begin{array}{c}\text { Absolute error } \\
\varepsilon_{D}(\mathrm{~nm}) \\
\end{array}$ \\
\hline Unmodified & 17.9 & 2.0 \\
\hline Modified with $12 \mathrm{~g} \mathrm{~L}^{-1}$ PEG 3350 & 15.7 & 1.6 \\
\hline Modified with $24 \mathrm{~g} \mathrm{~L}^{-1}$ PEG 3350 & 13.6 & 1.2 \\
\hline Modified with $12 \mathrm{~g} \mathrm{~L}^{-1}$ PEG 8000 & 18.1 & 2.1 \\
\hline
\end{tabular}

\section{Scanning electron microscopy}

Figure 5 shows the SEM micrographs of the 5-layered films prepared with and without PEG. The $\mathrm{TiO}_{2}$ film without PEG shows a flat and cracked structure whereas the films formed in the presence of PEG were crack-free and, because of the decomposition of the polymer with heat treatment (between 200 and $300{ }^{\circ} \mathrm{C}$, see Figure 3 ), developed a porous structure according to the amount and type of PEG employed. Pore sizes were in the ranges $200-350 \mathrm{~nm}$ and $350-600 \mathrm{~nm}$ for the films prepared from the sols with $12 \mathrm{~g} \mathrm{~L}^{-1} \mathrm{PEG}$ 3350 and $12 \mathrm{~g} \mathrm{~L}^{-1}$ PEG 8000, respectively. The apparent cracks for the film with $24 \mathrm{~g} \mathrm{~L}^{-1}$ PEG 3350 are actually interconnections of the pores that increase in number and diameter with increases in the amount of added PEG.

\section{Photocatalytic evaluation of films regarding methyl orange oxidation}

Figure 6 shows the effect of increasing the number of layers for

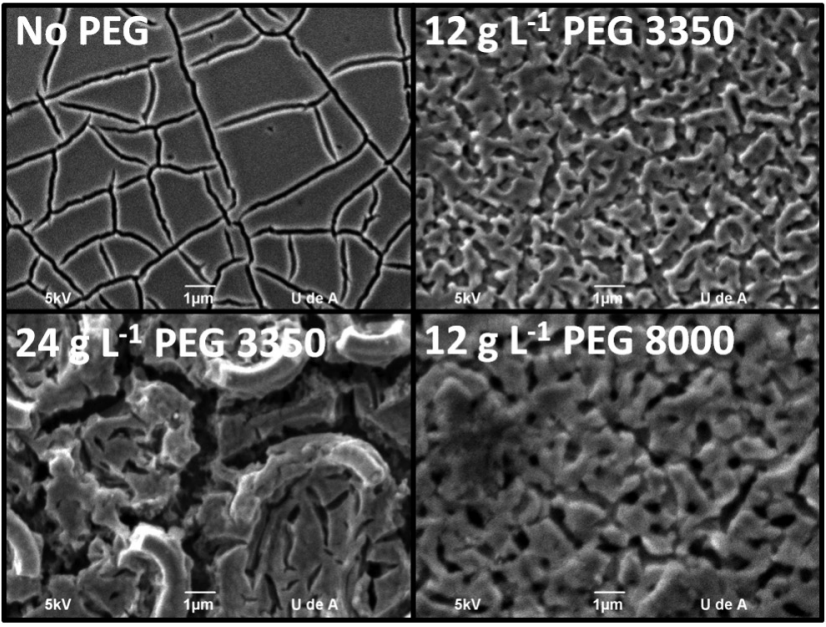

Figure 5. SEM images (10kX) obtained from the surface of the $\mathrm{TiO}_{2}$ films (5 layers). In the figure is indicated the PEG employed to modify the films

the four types of films on methyl orange oxidation for $2 \mathrm{~h}$. For the films without PEG, the methyl orange degradation increased with the number of layers up to the third layer, obtaining approximately the same value $(56 \%)$ for the film with 5 layers. On the other hand, the PEG-modified films did increase their yield with the increment in the number of layers in all cases, surpassing, in general, the yield of the film without PEG for the 3 and 5 layers. A maximum yield (79\%) was obtained for the 5-layered films with the use of $24 \mathrm{~g} \mathrm{~L}^{-1}$ PEG 3350.

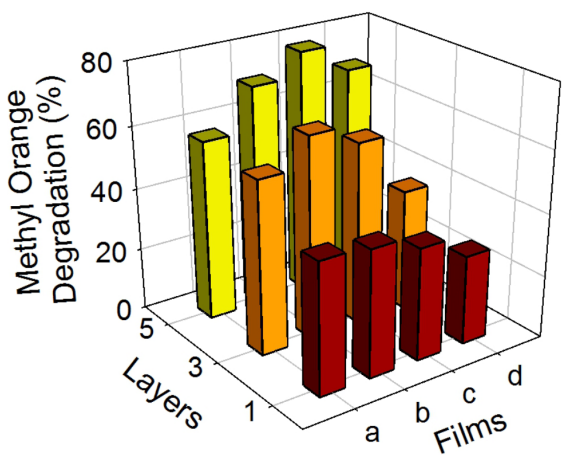

Figure 6. Methyl orange degradation vs. number of layers for the films with and without PEG: (a) no PEG, (b) $12 \mathrm{~g} \mathrm{~L}^{-1}$ PEG 3350, (c) $24 \mathrm{~g} \mathrm{~L}^{-1}$ PEG 3350, (d) $12 \mathrm{~g} \mathrm{~L}^{-1}$ PEG 8000

The different behaviours of the films, with and without PEG, is explained by the fact that photocatalysis is a surface process; therefore if the semiconductor film has low porosity, as is the case for the unmodified film, an increase in its thickness will not lead to a substantial improvement in its photocatalytic activity. By contrast, for those films with high porosity (PEG-modified films), interconnection between pores significantly increases the surface area of catalyst by increasing the thickness i.e. number of layers, which is ultimately reflected in enhanced photocatalytic activity.

Moreover, the molecular weight of the PEG proved to be another variable influencing reaction yield. In this regard, the use of a low molecular weight polymeric agent $\left(3350 \mathrm{~g} \mathrm{~mol}^{-1}\right)$ is more suitable. Because a lower molecular weight implies a smaller molecular size, during their elimination in the sintering stage of the film, smaller and more numerous pores are formed, yielding higher surface areas than when employing high molecular weight PEG.

In the results given in Figure 6, it is also evident that, for the thinner films (one layer), methyl orange photo-oxidation was greater 
for the unmodified film than the PEG-modified films. In this case, due to the thinness of the films, there are no pore interconnections within the films, causing the interfacial area of the unmodified film to be larger during the photocatalytic process.

Figure 7 shows the follow-up of the methyl orange oxidation up to $2 \mathrm{~h}$ of reaction time for the 5-layered films. Taking into account that, in general, the reaction rate decreases with colorant concentration, the concentration profile during the process was represented as an exponential function, ${ }^{24}$ Equation 2, while the kinetic constants $(k)$ were obtained by linear regression.

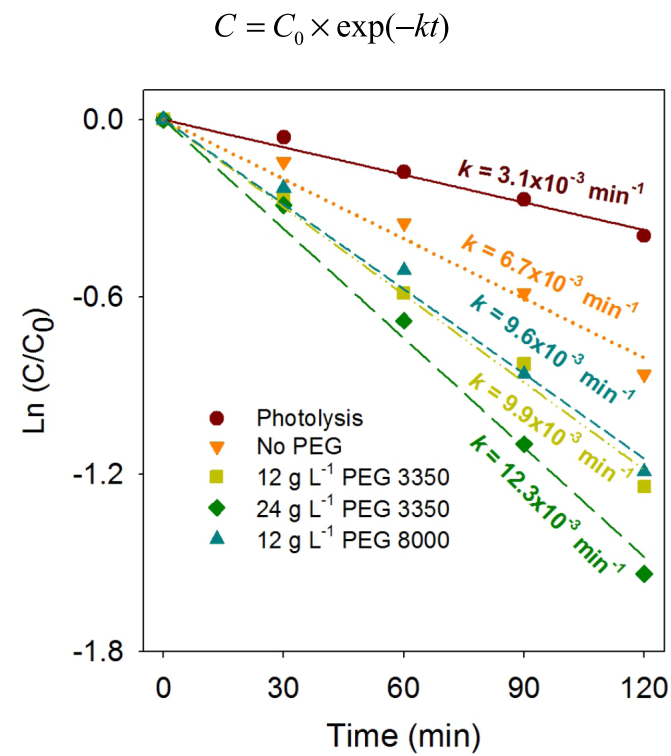

Figure 7. Variation of methyl orange concentration (relative to $C_{o}$ ) from aqueous solution at $25^{\circ} \mathrm{C}$ and treated with porous $\mathrm{TiO}_{2}$ films (5 layers) under heterogeneous photocatalysis conditions with irradiation time

The values of the kinetic constants obtained for the different photocatalytic runs (Figure 7) are of same order of magnitude for various photocatalytic reactions. ${ }^{17-20,25-27}$ Moreover, it is evident that the experimental data obtained for the $\mathrm{TiO}_{2}$ porous films (PEG-modified films) has good correlation with the exponential function for the pseudo first-order reaction $\left(R^{2}>0.99\right)$; whereas for the unmodified film (with low porosity) and the photolysis assay, the data has a better fit with zero-order kinetics, in which the reaction rate is independent of the colorant concentration. In these two assays, the diffusion of reactants does not control the reaction, and for the photocatalytic assay, stirring the solution is sufficient to keep the surface saturated with reactants. By contrast, in the modified films, reactants have to diffuse through the pores in order to reach the entire available surface for reaction, therefore diffusion substantially controls the kinetics of the reaction.

The kinetic constant for the photocatalytic test performed with the unmodified film $\left(6.7 \times 10^{-3} \mathrm{~min}^{-1}\right)$ is only twice that for the photolysis of methyl orange $\left(3.1 \times 10^{-3} \mathrm{~min}^{-1}\right)$. As mentioned above, this low photocatalytic activity of the unmodified film is related to its low porosity.

Given that kinetic constants for the assays with PEG-modified films of different molecular weight but equal concentration $\left(12 \mathrm{~g} \mathrm{~L}^{-1}\right)$ are practically the same $\left(9.9 \times 10^{-3}\right.$ and $9.6 \times 10^{-3} \mathrm{~min}^{-1}$, for PEG 3350 and 8000 , respectively), it is possible to infer that the pore size for this type of film is not a relevant parameter concerning photocatalytic activity. Conversely, increasing the concentration of PEG 3350 from 12 to $24 \mathrm{~g} \mathrm{~L}^{-1}$ led to a $24 \%$ increase in the kinetic constant, i.e. 9.9 $\times 10^{-3}$ to $12.3 \times 10^{-3} \mathrm{~min}^{-1}$. This is associated with increasing active sites for the photocatalytic reaction. In conclusion, the photoactivity of thick films is affected by the number of pores, but not by their size.

\section{CONCLUSIONS}

The use of polyethylene glycol as a polymeric fugitive agent in the fabrication of $\mathrm{TiO}_{2}$ films by the sol-gel method is an efficient method of producing porous thin films. By means of methyl-orange photo-oxidation tests, it was proven that the porosity of the films enhanced their photocatalytic activity. Increasing the number of layers (from 1 to 5) in the porous $\mathrm{TiO}_{2}$ film causes an increase in its photocatalytic response if the generated pores are open, i.e. when they are interconnected, allowing the diffusion of reactants and products. Films with greatest photocatalytic activity were obtained by the addition of PEG with a molecular weight of $3350 \mathrm{~g} \mathrm{~mol}^{-1}$ and concentration of $24 \mathrm{~g} \mathrm{~L}^{-1}$. Polymeric agents with a very high molecular weight (such as $8000 \mathrm{~g} \mathrm{~mol}^{-1}$ ) lead to the formation of overly large pores, but are not associated with any significant variation in photocatalytic activity of the films; indicating that pore size is not a relevant parameter concerning photocatalytic activity.

\section{SUPPLEMENTARY MATERIAL}

Available at http://quimicanova.sbq.org.br, in pdf file, with free access.

\section{ACKNOWLEDGEMENTS}

The authors express their acknowledgements to COLCIENCIAS (Project 1102-521-28875) and the Vicerrectoría de Investigación y Extensión from the Universidad Industrial de Santander (project 9416), for the financial support of this investigation.

\section{REFERENCES}

1. Lee, A. C.; Lin, R. H.; Yang, C. Y.; Mater. Chem. Phys. 2008, 109, 275.

2. Brunelli, T. F. T.; Guaraldo, T. T.; Paschoale, F. M. M.; Zanoni, M. V. B.; Quim. Nova 2009, 32, 67

3. Rengifo-Herrera, J. A.; Pulgarín, C.; Machuca, F.; Sanabria, J.; Quim. Nova 2010, 33, 1636.

4. Mardare, D.; Tasca, M.; Delibas, M.; Rusu, G. I.; Appl. Surf. Sci. 2000, 156, 200.

5. Acevedo-Peña, P.; Vázquez, G.; Laverde, D.; Pedraza-Avella, J. E.; Manríquez, J.; González, I.; J. Electrochem. Soc. 2009, 156, 377.

6. Peralta-Ruiz, Y. Y.; Lizcano-Beltran, E. M.; Laverde, D.; Acevedo-Peña, P.; Córdoba, E. M.; Quim. Nova 2012, 35, 499.

7. Gelover, S.; Mondragon, P.; Jimenez, A.; J. Photochem. Photobiol., A 2004, 165, 241

8. Murugavel, P.; Kalaiselvam, M.; Raju, A.; J. Mater. Chem. 1997, 7, 1433.

9. Arconada, N.; Duran, A.; Suarez, S.; Appl. Catal., B 2009, 86, 1.

10. Deepa, M.; Saxena, T. K.; Singh, D. P.; Sood, K. N.; Agnihotry, S. A.; Electrochim. Acta 2006, 51, 1974.

11. Guo, B.; Liu, Z.; Hong, L.; Jiang, H.; Lee, J. Y.; Thin Solid Films 2005, 479, 310 .

12. Liau, L. C-K.; Chang, H.; Yuang, T. C-K.; Huang, C-L.; J. Chin. Inst. Chem. Eng. 2008, 39, 237.

13. Mohammadi, M. R.; Cordero-Cabrera, M. C.; Fray, D. J.; Sens. Actuators, $B$ 2006, 120, 86

14. Černigoj, U.; Štangar, U. L.; Trebse, P.; Thin Solid Films 2006, 495, 327.

15. Guo, B.; Liu, Z.; Hong, L.; Jiang, H.; Surf. Coat. Technol. 2005, 198, 24.

16. Al-qaradawi, S.; Salman, S. R.; J. Photochem. Photobiol., A 2002, 148, 161.

17. Guettaï, N.; Amar, H. A.; Desalination 2005, 185, 427.

18. Guettaï, N.; Amar, H. A.; Desalination 2005, 185, 439.

19. Chen, L-C.; Chou, T-C.; J. Mol. Catal. 1993, 85, 201. 
20. Negishi, N.; Takeuchi, K.; Thin Solid Films 2001, 392, 249.

21. Arabatzis, I. M.; Antonaraki, S.; Stergiopoulos, T.; Hiskia, A.; J. Photochem. Photobiol., A 2002, 149, 237.

22. Sonawane, R. S.; Hedge, S. G.; Dongare, M. K.; Mater. Chem. Phys. 2002, 77, 744 .

23. Avellaneda, C. O.; Aegerter, M. A.; Pawlicka, A.; Quim. Nova 1998, 21, 365 .
24. Konstantinou, I. K.; Albanis, T. A.; Appl. Catal., B 2004, 49, 1.

25. Mathews, N. R.; Morales, E. R.; Cortés-Jacome, M. A.; Toledo, J. A.; Sol. Energy 2009, 83, 1499.

26. Guilherme Garcia, B.; Pacheco Santos, V.; Lindino, C. A.; Quim. Nova 2012, 35, 332.

27. Li, W.; Li, D.; Lin, Y.; Wang, P.; Chen, W.; Fu, X.; Shao, Y.; J. Phys. Chem. C 2012, 116, 3552. 


\section{ENHANCED PHOTOCATALYTIC ACTIVITY OF TiO, FILMS BY MODIFICATION WITH POLYETHYLENE} GLYCOL

Álvaro A. Ramírez-Santos, Próspero Acevedo-Peña and Elcy M. Córdoba*

Universidad Industrial de Santander, Calle 9 Cra. 27, Postal code 678 Bucaramanga (Santander), Colombia

\section{UV-VIS SPECTROSCOPY CHARACTERIZATION OF TIO, FILMS}

The spectra for the films with 1,3 and 5 layers prepared from the different sols are showed in the Figure 1S. It can be observed that as the number of layers increases the films become less transparent, due to a greater light interference caused by the thickness of the films, ${ }^{1}$ which allows the less energetic radiations to be absorbed as well in the visible and low energy UV range. This causes the characteristic $\mathrm{TiO}_{2}$ absorption peak (between 300 and $375 \mathrm{~nm}$ ) to both increase its height and expand towards greater wavelenghts. This tendency is quite evident for the films obtained from the $12 \mathrm{~g} \mathrm{~L}^{-1}$ PEG 8000 modified sol, which generated very opaque films, even with one layer, as observed in the Figure 7b. In general, the PEG modified $\mathrm{TiO}_{2}$ films (Figures 1Sbd) showed peaks in wave patterns in the range of 310 to $800 \mathrm{~nm}$ approximately.

The band-gap energies of the $\mathrm{TiO}_{2}$ films were estimated from Figure $1 \mathrm{~S}$ and are summarized in the Table 1S. The redshift of the absorption edge of the $\mathrm{TiO}_{2}$ films produced by the increase in the number of dippings, involves a decrease of the bandgap energies
$\left(E_{\mathrm{g}}\right)$ from $3.55 \mathrm{eV}$ (1 layer) to $3.32 \mathrm{eV}$ (5 layers) for the unmodified $\mathrm{TiO}_{2}$ film and from $3.60 \mathrm{eV}$ (1 layer) to $3.41 \mathrm{eV}$ (5 layers) for the film obtained with the $24 \mathrm{~g} \mathrm{~L}^{-1}$ PEG 3350 modified sol (Table 1S). ${ }^{2}$ However, due to the small shift observed in the band-gap energies, it can be assumed that the employ of PEG for obtain porous $\mathrm{TiO}_{2}$ films, do not modify the $\mathrm{TiO}_{2}$ electronic structure, or

Table 1S. Band-gap energies estimated for the formed $\mathrm{TiO}_{2}$ films

\begin{tabular}{|c|c|c|}
\hline $\mathrm{TiO}_{2}$ Film & $\lambda(\mathrm{nm})$ & $E_{g}(\mathrm{eV})$ \\
\hline Unmodified - 1 layer & 350 & 3.55 \\
\hline Unmodified - 3 layers & 370 & 3.36 \\
\hline Unmodified - 5 layers & 375 & 3.32 \\
\hline Modified with $24 \mathrm{~g} \mathrm{~L}^{-1}$ PEG 3350 - 1 layer & 345 & 3.60 \\
\hline Modified with $24 \mathrm{~g} \mathrm{~L}^{-1}$ PEG $3350-3$ layers & 352 & 3.53 \\
\hline Modified with $24 \mathrm{~g} \mathrm{~L}^{-1}$ PEG $3350-5$ layers & 365 & 3.41 \\
\hline
\end{tabular}
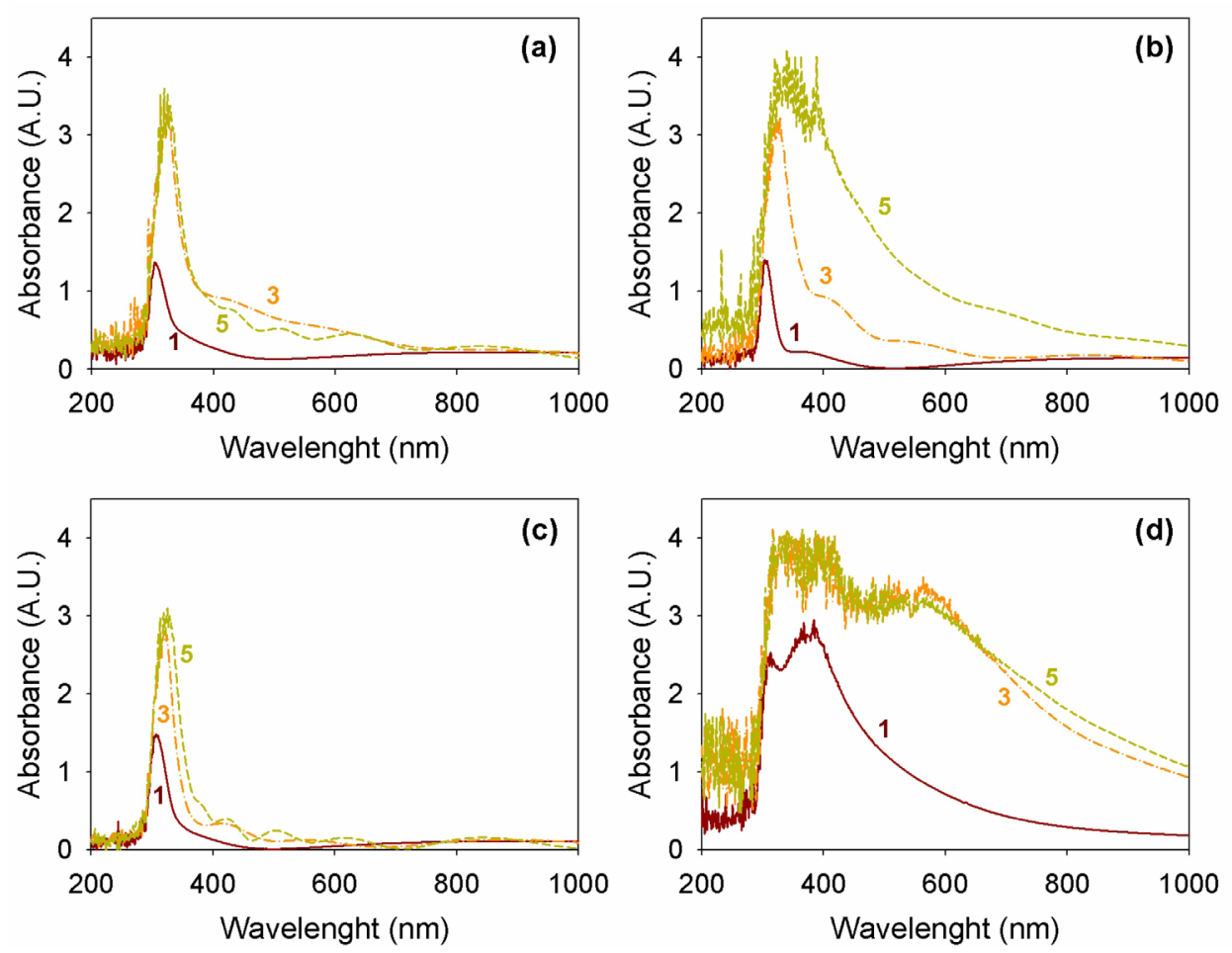

Figure 1S. Effect of the number of layers (1, 3 and 5 layers) on the light absorption of the TiO ${ }_{2}$ films : (a) No PEG, (b) $12 \mathrm{~g} \mathrm{~L} L^{-1}$ PEG 3350 , (c) $24 \mathrm{~g} L^{-1}$ PEG 3350, (d) $12 \mathrm{~g} \mathrm{~L}^{-1}$ PEG 8000

*e-mail: ecordoba@uis.edu.co 
induce states inside the bandgap of the semiconductor. The bandgap energies for the remaining films (films prepared with sols modified with $24 \mathrm{~g} \mathrm{~L}^{-1}$ PEG 3350 and $12 \mathrm{~g} \mathrm{~L}^{-1}$ PEG 8000) were not calculated due to their opacity.

The increase of PEG concentration in the sol from 0 to $12 \mathrm{~g} \mathrm{~L}^{-1}$ also causes an increase in the absorbance of the $\mathrm{TiO}_{2}$ films, due to the scattering of light by the pores generated by the organic compound (Figures $1 \mathrm{Sa}, \mathrm{b}, \mathrm{d}$ ). However, a posterior increase of PEG concentration from 12 to $24 \mathrm{~g} \mathrm{~L}^{-1}$, carries a decrease in the absorbance of the films, which is due to the increment of the diameter and of the interconnection of the pores (Figures $1 \mathrm{Sa}, \mathrm{c}$ ). This indicates that the differences in absorbance among the films are due to the differences in the size and interconnection of the pores and to the thickness of films.

\section{REFERENCES}

1. Negishi, N.; Takeuchi, K.; Ibusuki, T.; J. Mater. Sci. 1998, 33, 5789.

2. López, T.; HenándezVentura, J.; Gómez, R.; Tzompantzi, F.; Sánchez, E.; Bokhimi, X.; García, A.; J. Mol. Catal., A 2001, 167, 101. 